\title{
Châteaux romantiques, études réunies et présentées par Pascale Auraix-Jonchière et Gérard Peylet
}

\section{Marie-Thérèse Périn}

\section{(2) OpenEdition}

1 Journals

\section{Édition électronique}

URL : http://journals.openedition.org/studifrancesi/9575

DOI : 10.4000/studifrancesi.9575

ISSN : 2427-5856

Éditeur

Rosenberg \& Sellier

\section{Édition imprimée}

Date de publication : 1 décembre 2007

Pagination : 669-670

ISSN : 0039-2944

\section{Référence électronique}

Marie-Thérèse Périn, «Châteaux romantiques, études réunies et présentées par Pascale AuraixJonchière et Gérard Peylet », Studi Francesi [En ligne], 153 (LI | III) | 2007, mis en ligne le 30 novembre 2015, consulté le 08 janvier 2021. URL : http://journals.openedition.org/studifrancesi/9575; DOI : https://doi.org/ERREUR PDO dans /localdata/www-bin/Core/Core/Db/Db.class.php L.34 SQLSTATE[HYO00] [2006] MySQL server has gone away

Ce document a été généré automatiquement le 8 janvier 2021.

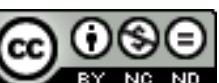

Studi Francesi è distribuita con Licenza Creative Commons Attribuzione - Non commerciale - Non opere derivate 4.0 Internazionale. 


\title{
Châteaux romantiques, études réunies et présentées par Pascale Auraix- Jonchière et Gérard Peylet
}

\author{
Marie-Thérèse Périn
}

\section{RÉFÉRENCE}

AA. VV., Châteaux romantiques, études réunies et présentées par Pascale AURAIX-JONCHIÈRE et Gérard PEYLET, Cahiers du Laboratoire Pluridisciplinaire de recherches sur l'Imaginaire appliquées à la Littérature (L.A.P.R.I.L.), Presses Universitaires de Bordeaux, 2004, pp. 363.

1 Le colloque Châteaux romantiques invite le lecteur à une approche plurielle de l'architecture castrale, selon des axes historiques, littéraires et esthétiques, dont nous analysons ici seulement les communications portant sur la première moitié du xix ${ }^{e}$, malgré la présence d'autres fort intéressantes sur la fin de siècle (notamment celles de Catherine Botterel-Michel et Gérard Peylet).

2 En toute logique, le volume s'ouvre sur une volonté de définition du «château romantique» qui retourne aux sources proposées par le Grand Dictionnaire universel $d u$ XIX ${ }^{e}$ siècle de Larousse et le Dictionnaire raisonné de l'architecture de Viollet-le-Duc, pour les confronter aux perceptions des écrivains romantiques. Jacques NOIRAY (pp. 19-28) et Lue FRAISSE (pp. 29-56) insistent sur la vie seigneuriale, dominée par l'ennui, l'isolement et les habitudes de rêverie, telle que les écrivains romantiques la perçoivent au sein de la demeure féodale. Au-delà de la fonction mémoriale traditionnelle, Françoise BERCEGOL (pp. 57-68) révèle les réactions contrastées d'imitation ou d'affranchissement qui animent Flaubert, Le Braz, Du Camp, Barrès, Le Guillou en pèlerinage à Combourg, dans leur vénération envers le maître Chateaubriand: par eux, l'architecture du château est alors parcourue du regard, avant d'être lue comme une œuvre dont il s'agit d'élucider les principes de création. 
3 Pascale AURAIX-JONCHIÈRE (pp. 79-94) démontre le caractère paradoxal des châteaux de George Sand et le caractère duel de son écriture à leur propos. Carme FIGUEROLA (pp. 117-132) considère le motif du château dans l'œuvre de son amant Jules Sandeau: à ses yeux, cette demeure dont la description est à peine esquissée dépasse le statut de décor; l'intrigue s'organise essentiellement dans le château et ses annexes, reflétant ainsi les usages de l'époque, les rapports sociaux au temps de Sandeau et traduisant en fait son idéologie. C'est avec surprise que le lecteur voit ensuite Versailles considéré comme un château romantique par Laurent GiRAUD (pp. 133-144): pour éclairer ce paradoxe, il met en lumière les éléments qui, dans les Mémoires d'un médecin de Dumas, déterminent une zone dramatique où se vivent solitude et fureur des passions, ce qui «brise les destins des héros» (p. 133).

4 La voie est ainsi ouverte à l'étude «des orages désirés» romantiques jusque dans leur «nuit intérieure» (p. 145). Dans ce contexte, Janine GUICHARDET (pp. 147-158) inscrit la demeure campagnarde de Mlle des Touches, dans Béatrix de Balzac: elle déchiffre «les symboles ambivalents, contradictoires dans ce lieu d'aventures et d'initiation» (p. 147), de méditation et de révélation progressive. «Les châteaux de légende dans Inès de la Sierras» (pp. 159-176) suscitent la réflexion de Barbara DIMOPOULou: à partir de l'écriture minutieuse de Nodier, elle met en valeur la spécificité du château de Ghismondo et situe l'œuvre dans la veine du roman gothique. Angels SANTA (pp. 177-188), quant à elle, étudie le premier roman de Dumas, Pauline, et se propose de «constater le pouvoir de la fascination de l'image du château sur l'écrivain» (p. 178): les châteaux blancs et protecteurs de sa jeunesse conduisent l'héroïne fatalement vers son destin; solitude, angoisse et terreurs croissantes laissent place ensuite au château noir mythique du romantisme: là s'impose l'homme fatal - son mari.

5 Au Maine-Giraud où se tenait le colloque, Yolande LEGRAND (pp. 241-252) se devait de retracer l'inspiration suscitée par son manoir dans la création de Vigny: différenciant les deux premiers passages rapides du poète de ses séjours plus tardifs, elle explore les Mémoires et la Correspondance et démontre comment le site ne fait que révéler des formes littéraires prédessinées dans l'imaginaire du mémorialiste. Lise SABOURIN étend son champ d'investigation à «L'imaginaire du château chez Alfred de Vigny: du motif décoratif au symbole» (pp. 253-268). Elle remarque combien les descriptions des châteaux sont rapides, dépourvues de connotations pittoresques, mais prouve que certains motifs architecturaux privilégiés prennent une force symbolique par leur récurrence, tels fenêtre, balcon et donjon: de l'un de ces postes d'observation en position sommitale, le héros contemple la nature et perçoit les vicissitudes humaines qui déterminent les destins individuels. Prolongeant la vision du processus créateur, elle élargit son propos à l'art: Vigny fait du «livre, château de l'esprit, [la] seule trace durable de la réflexion humaine» (p. 266). Pour reprendre l'expression de Wladimir TROUBETZKoy (pp. 269-278), «quoi de plus différent de Combourg que le Maine-Giraud?»: il ose cependant dresser la comparaison entre ces deux lieux qui permettent à leurs auteurs la mise en scène de soi et l'évolution de l'être au travers de mots maîtrisés.

6 Abordant également la constitution du moi autobiographique, Éric FRANCALANZA (pp. 279-294) se penche lui aussi sur les diverses images de château sandien et se demande si ses demeures, notamment Nohant, représentées dans Histoire de ma vie constituent l'emblème de sa vision du xviii ${ }^{e}$ siècle. L'image du château féodal, majoritaire dans l'œuvre de Gautier, donne l'occasion à Anne GEISLER-SZMULVICZ (pp. 295-308) de clarifier son processus d'écriture poétique ou romanesque: il fait de la bâtisse fortifiée «le lieu 
privilégié de la création ou re-création» (p. 303), ce qui le conduit à associer la restauration archéologique à une résurrection imaginaire des êtres liés à ces emplacements du passé, qui permet «une plongée en soi-même» (p. 307). C'est donc d'intériorité qu'il est question au travers de l'architecture, ce que discerne également Myriam ROMAN dans le récit de voyage hugolien: le motif récurrent des «burgs en mine dans Le Rhin (1842)» (pp. 347-363) convoque la théorie de Gilpin dans ses Trois Essais sur le beau pittoresque (1792) et valorise le rôle structurant du château dans la description et le regard.

7 Toute la fascination du Moyen Âge chez les auteurs romantiques s'exprime donc au travers de son élément vital: le château, vu sous les perspectives croisées et complémentaires des contributeurs de ce volume qui se rapprochent parfois de la démarche de l'historien, tout en laissant place à l'étude des caractères créateurs et en aboutissant à discerner les arcanes de «la citadelle de l'écriture». 